\title{
Mycotic Keratitis, a State-of-the-Art Review
}

\author{
Parisa Badiee ${ }^{1, *}$ \\ ${ }^{1}$ Prof. Alborzi Clinical Microbiology Research Center, Shiraz University of Medical Sciences, Shiraz, IR Iran \\ ${ }^{*}$ Corresponding author: Parisa Badiee, Prof. Alborzi Clinical Microbiology Research Center, Nemazi Hospital, Zand Ave, Shiraz, IR Iran, Postal Code 7193711351. Tel: +98-7116474292, Fax: \\ +98-7116474303, E-mail: badieep@sums.ac.ir.
}

Received: October 13, 2012; Revised: January 13, 2013; Accepted: January 22, 2013

\begin{abstract}
Microbial corneal diseases are a serious ocular infection and the major cause of ocular morbidity and blindness in the world. Theoutcomes of fungal keratitis are unfavorable due to the protracted course of the condition and the diversity of respective clinical presentations. Trauma, contact lens wear, foreign material, and prior corneal surgery, may make the most background for permitting invasion by exogenous fungi by injecting the fungal conidia directly in the corneal stroma. Other risk factors consist of blocked naso-lacrimal duct, and ocular surface disease. More than 105 species of fungi, such as Aspergillus spp., Fusarium spp., Candida spp., Rhizopus, Mucor, and other fungi have been identified as the etiological agents of fungal keratitis.

The first step of diagnosis begins with clinical suspicion, followed by corneal scrapings or biopsy for direct smear and culture confirming the etiological agent. Slit lamp biomicroscope is used for careful examination of the infected eye and pictorial documents like the ulcer size, site, depth, extent of infiltration, abscess formation, and any perforation are evaluated. Direct smears are prepared by potassium hydroxide wet mount, or Gram's staining. To identify the isolates, a lactophenol cotton blue wet mount is prepared, and diagnosis is based on morphology of the culture media and details of microscopic examination.

The results are highly specific but have suboptimal sensitivity varying in different studies. Molecular assays are valuable for the diagnosis of fungal keratitis in patients. Various advantages and limitations are reported for such methods. Overall, PCR is a sensitive and promising tool for the diagnosis of fungal keratitis but the expertise required and the lack of sophisticated facilities renders it inferior to the smear techniques in routine laboratory procedures and is not recommended accordingly.

Rapid diagnosis and proper treatment are essential for fungal keratitis, and many patients require several months of therapy until the infiltrate is resolved and epithelial stroma are healed. Patients not responsive to antifungal therapy usually require corneal transplantation.
\end{abstract}

Keywords: Corneal Ulcer; Keratitis; Eye Infections

\section{Background}

Microbial corneal diseases are serious ocular infections and the major cause of ocular morbidity and blindness in the world with occurring record of about two million corneal ulcers annually (1). The rate of infections in third-world countries like South Africa and Ghana (2) is 30 times the number of corneal ulcers in the United States (3). The outcomes of the FK are unfavorable due to the protracted course of the condition and the diversity of clinical presentations (4), therefore, the ophthalmologists encounter the greatest challenge in diagnosis and treatment. The signs of FK can cause a deep and severe corneal ulcer with small satellite lesions around it and hypopyon may be seen. Clinical symptoms are nonspecific, with slower onset and more gradual progression than that of bacterial infections $(5,6)$. With precise clinical examination, ophthalmologists may reach rapid, presumptive and highly predictive diagnosis, and thus, can select empirical antifungal treatments with better outcomes. The external ocular conditions include pain, redness, dry eyes, bullous keratopathy adnexal abnormalities such as trichiasis and entropion, blepharitis lid edema, abnormalities and conjunctival congestion corneal degeneration and defective vision. Biomicroscopic findings with slit-lamp can measure the diameter of the size of the inflammatory infiltrate, and evaluate the type, location, depth of ocular inflammation and corneal ulceration, an anterior midstromal infiltrate with feathery border and surrounding edema, loss of the corneal epithelium with suture and underlying stromal infiltration. Briefly, they vary considerably and no characteristic features can be absolutely pathognomonic for the diagnosis of etiological agent of infective ulcer. A sensitivity of up to $83 \%$ has been reported by Thomas et al. (7) for diagnosing FK along with consideration of respective clinical features. The presence of clinical symptoms with duration of in-

Implication for health policy/ practice/ research/medical education:

Rapid diagnosis andproper treatment are essential for fungal keratitis, and many patients require several months of therapy until the infiltrate is resolved and epithelial stroma is healed. Patients not responsive to antifungal therapy usually require corneal transplantation.

Copyright (C) 2013, Ahvaz Jundishapur University of Medical Sciences; Licensee Kowsar Ltd. This is an Open Access article distributed under the terms of the Creative Commons Attribution License (http://creativecommons.org/licenses/by/3.0), which permits unrestricted use, distribution, and reproduction in any medium, provided the original work is properly cited. 
fection and potential risk factors may help the ophthalmologists with rapid diagnosis.

Fungal corneal ulcers like other fungal infections are commonly present in immunocompromised patients but they have also been reported in healthy humans (8). This infection may occur at any age and for any sex but the most susceptible group are males engaged in agricultural or other outdoor work at the age of 31 to 40 years. In one study, $53.7 \%$ of mycotic keratitis cases were farmers and laborers (9). Environmental factors like humidity, rainfall, and wind, influence the occurrence of FK. Significant systemic predisposing factors include diabetes, human immunodeficiency virus, treatment for a bacterial infection with antibiotics or steroids (10). Corneal trauma with plant material, animal origin and even dust particles appeared to be the most common predisposing factors (9). Other risk factors consist of blocked nasolacrimal duct, poor hygiene practice in soft contact lens wearers, and ocular surface disease.

Trauma, contact lens wear, foreign material and prior corneal surgery may make the background for permitting invasion by exogenous fungi by injecting the fungal conidia directly in the corneal stroma. After contamination with fungal elements, fungi gain access to the anterior chamber or the posterior segment and with specific mechanisms such as proteolytic enzymes and mycotoxins damage the tissue. Filamentous fungi like Aspergillus and Fusarium spp. are able to proliferate and spread within the corneal stroma and penetrate the descemet membrane. In contrast, Candida albicans release chemotactic substances such as phospholipase A and lysophospholipase and facilitate entrance in to the tissue $(11,12)$. These organisms can extend from the cornea into the sclera and intraocular structures and cause severe infections, like anophthalmitis, scleritis, and endophthalmitis.

\section{Etiologic Agents}

More than 105 species of fungi, such as Aspergillus spp. Fusarium spp., Candida spp., Rhizopus, Mucor, and other fungi (13) have been identified as the etiological agents of FK. Theses agents include yeast (particularly Candida) and filamentous fungi. Candida albicans keratitis is an opportunistic infection of a compromised cornea, and sometimes unknowingly compromised host, which can be initially misdiagnosed. Candida albicans is found in the normal flora of different human body sites like mouth and gastrointestinal tract, therefore, eyes can be contaminated with fingers, and then false-positive results are obtained in the culture media for Candida albicans. Thus, clinical funding is important for the treatment of Candida infection.

Filamentous fungi (especially Fusarium and Aspergillus) are frequent causes of fungal corneal ulcers. Filamentous agents vary, depending on the geography and climate of each region. Aspergillus species was the most common isolate in the FK reported in India $(14)$, south Iran $(15,16)$
Nepal, and Bangladesh (17). However, certain Aspergillus species, mainly A. flavus (16), A. terreus (18), A. fumigatus (19), and A. niger (20), have long been regarded as important pathogens in FK. Fusarium species was found to be the most common cause of FK in south India (21), but the prevalence of the infection in other parts of the world is limited (16).

\section{Epidemiology}

The epidemiological variation and wide geographical distributions are related to the economic and climate factors (22). Considering such factors, FK account for approximately $28 \%$ of ulcerative keratitis, ranging from $6 \%$ to $53 \%,(18,23)$ and FK rate is about $50 \%$ in culture-proven cases $(24)$

\section{Diagnosis of Fungal Keratitis}

Early diagnosis of FK is important for the management and prevention of further complications such as loss of vision, hypopyon formation, endopthalamitis and for complete recovery (25). The first step of diagnosis begins with clinical suspicion, then, corneal scrapings or biopsy for direct smear and culture are performed to confirm the etiological agent. Slit lamp bio-microscopeis used for careful examination of the infected eye and pictorial documents like the ulcer size, site, depth, extent of infiltration, abscess formation, and any perforation are evaluated. For specimen collection after the instillation of anesthetic eye drops such as proxymetacaine hydrochloride, corneal scrapings from the base and margin of the ulcers are collected aseptically, using a metal blade under direct vision through a slit-lamp. It is optimum for samples to be collected in the first visit, before using of antimicrobial or antifungal agents.

Direct smears are prepared by potassium hydroxide (KOH) wet mount, or Gram's staining. Different high sensitivity rates have been reported for $\mathrm{KOH}$ wet mount including $61 \%$ (26), 76.3\% (21), 71.4\% (27), and 90\% (28). However, a much lower sensitivity of $33 \%$ was also reported from another study (29). Gram's smear sensitivity is lower than that of $\mathrm{KOH}$ wet mount because the former is not specialized for fungi and there are reports indicating sensitivity; $60 \%$ (26) $42.9 \%$ (27) and $42.1 \%$ (21).There are other stains, namely, acridine orange, and Giemsa staining used for the diagnosis of FK. Correct sampling and expert diagnosis laboratory, if provided, can lead to faster and more efficient screening.

For identification of the isolates, a lactophenol cotton blue wet mount is prepared, and diagnosis is based on the morphology of cultural media and details of microscopic examination. The results are highly specific but have suboptimal sensitivity varying in different studies; 68.4\% (21), $37.5 \%$ (20) and $25 \%$ (30). Although culture is considered as the gold standard for FK diagnosis, the major limitations are the length of time consumed for confirming the culture growth because the fungi often have a slow growth, 
and a high chance of culture media contamination. The major advantage of culturing the samples is determining the sensitivity pattern of the isolates, because many fungi are resistant to the routine antifungal agents (3133). Depending on the type of cornea specimen, stain and culture were positive in $80 \%$ of the biopsies and in $61.9 \%$ and $52.4 \%$ of the corneal scrapings, respectively (34).

For the diagnosis of FK, use of a serological method and detection of antigen or antibody in serum is limited because of the localized infection. In immunocompromised patients, these methods may prove useful if the infection becomes systemic. There are many reports about molecular assays for the detection of systemic fungal infections using punfungal PCR with the available DNA primer sets for the recognition of all fungal species (35), nested PCR $(36,37)$ and real time PCR $(38-40)$. Molecular assays can serve as a valuable method for the diagnosis of FK in experimental animal infections and patients (41-43).

The sensitivities of molecular assays (PCR) in FK which documented by culture results for fungi in some studies were reported to be $81.6 \%$ (21) and 70\% (30). Advantages of these methods include the ability to detect fungal DNA for the majority of fungal corneal ulcers with negative culture, and by using the DNA sequencing or specific primers, novel organisms can be detected in culture-negative cases. Also, these methods are able to detect fungal elements in the treated patients. For 10 out of 40 eyes pretreated with antifungal agents, PCR was positive in 50\%, but culture in $30 \%$ of the cases (30). Real time PCR has the ability to quantify the load of the organism and can serve as the treatment follow up.

There are many logistic and technical limitations in the use of various molecular assays for the detection of FK, such as differentiating between active and latent infections, viable and nonviable organisms especially after treatment, and difficulty in optimization according to the type of fungi. False positive results may also occur during the DNA sequencing due to the high sensitivity of this method, although attention to reducing falsepositive results from contaminating DNA is warranted (44). Contamination of samples may occur in each stage of sampling or in reagents during processing of positive control specimens and amplification of nonpathogenic organisms. Another limitation in the widespread utility of these techniques as a screening test is not being cost effective.

Use of panfungal PCR for the identification of fungal species is not enough and various primers or sequencing are needed. This procedure is expensive for the patients and not available in routine laboratories. There are reports on the time required for positive fungal cultures, being at least 5 to 7 days (30) or at least 1 to 35 days (34), whereas PCR assay requires only 4 to 8 hours $(30,34)$. However, in practice the time needed for multi PCR or sequencing of the amplified DNA exceeds such lengthsand sometimes makes these techniques slower than the traditional ones (19). Overall, PCR is a sensitive and promising tool for the diagnosis of FK but the expertise required and the lack of sophisticated facilities render it inferior to the smear techniques in routine laboratory procedures and is not recommended accordingly.

\section{Treatment of Fungal Keratitis}

Unfortunately, delays in appropriate treatment and use of topical antibiotics and corticosteroids are risks for development of blindness due to delays in antifungal therapy in patients with FK. This may result in corneal perforation, and Keratoplasty is performed. As the appearance of the ulceration for distinguishing fungal from bacterial ulcer is unreliable (45) and since resistant fungi have been reported $(33,46)$, treatment on the basis of correct identification of pathogen by culture and determination of sensitivity could have better outcomes than empirical treatment with broad-spectrum antibiotics. Culture results are also critical to tailor therapy for patients who fail empirical therapy.

Natamycin is the polyene antifungal agent approved by the Food and Drug Administration, as the first line therapy for the treatment of FK since the 1960s. There are occasional reports of natamycin resistant Aspergillus spp. isolated from infected eyes (47) or natamycin unresponsiveness in patients with mycotic keratitis (48). Amphotericin B topical form or voriconazole are used for the treatment of suspected cases of FK caused by filamentous fungi reported in numerous case reports in the ophthalmic literature (49-51). There has not been any reports for significant differences in scar size, visual acuity, and perforations between use of natamycin or voriconazole for treatment of patients (51).

Poor penetration of natamycin in intact epithelium, was reported while voriconazole had superior permeability through the epithelium (51-54). Totally, natamycin suspension $(5 \mathrm{mg} / \mathrm{mL})$ is the drug of choice for topical therapy, although amphotericin B drops $(1.5 \mathrm{mg} / \mathrm{mL})$ have also been used (55). Topical voriconazole is increasingly favored among ophthalmologists because of its wide spectrum of coverage against yeasts and filamentous agents of FK (56). In immune-compromised patients and in those with severe infections, the treatment includes a topical antifungal agent combined with systemic antifungal medications (55). Successful treatment with oral posaconazole has been reported in three patients who did not respond to the treatment with voriconazole (57). Intracorneal injections of voriconazole in patients not responsive to topical and systemic therapy were also reported $(58,59)$. Topical agents should initially be applied hourly with subsequent modification based upon the response. Prolonged therapy for approximately four weeks is usually necessary (60). Many patients require several months of therapy until the infiltrate is resolved and epithelial stroma is healed. Patients who do not respond to antifungal therapy usually require corneal transplanta- 
tion.

\section{Conclusions}

Fungi have long been regarded as important pathogens in keratitis. Early diagnosis and treatment can be helpful for the management of this infection. In doing so, use of traditional techniques and molecular diagnosis may be beneficial. But use of conventional methods is recommended in the first line of diagnosis and in cases with negative results, molecular methods are recommended.

\section{Acknowledgements}

We thank H. Khajehei for his help with linguistic copy editing.

\section{Financial Disclosure}

None Declared

\section{Funding/Support}

This work was supported by Prof. Alborzi Clinical Microbiology Research Center, Shiraz University of Medical Sciences, Shiraz, Iran.

\section{References}

1. Whitcher JP, Srinivasan M, Upadhyay MP. Corneal blindness: a global perspective. Bull World Health Organ. 2001;79(3):214-21.

2. Whitcher JP, Srinivasan M, Upadhyay MP. Prevention of corneal ulceration in the developing world. Int Ophthalmol Clin. 2002;42(1):71-7.

3. Upadhyay MP, Karmacharya PC, Koirala S, Shah DN, Shakya S, Shrestha JK, et al. The Bhaktapur eye study: ocular trauma and antibiotic prophylaxis for the prevention of corneal ulceration in Nepal. Br JOphthalmol. 2001;85(4):388-92.

4. Bharathi MJ, Ramakrishnan R, Meenakshi R, Padmavathy S, Shivakumar C, Srinivasan M. Microbial keratitis in South India: influence of risk factors, climate, and geographical variation. Ophthalmic Epidemiol. 2007;14(2):61-9.

5. Barnes SD, Pavan Langston D, Azar DT, Mandell GL, Bennett JE, Dolin R. Microbial keratitis. In: Barnes SD, Pavan Langston D, Azar DT, Mandell GL, Bennett JE, Dolin R, editors.Mandell, Douglas, and Bennett's Principles and Practice of Infectious Diseases.Philadelphia: Churchill Livingstone Elsevier; 2010. p. 1539.

6. Riddell Iv J, McNeil SA, Johnson TM, Bradley SF, Kazanjian PH, Kauffman CA. Endogenous Aspergillus endophthalmitis: report of 3 cases and review of the literature. Medicine (Baltimore). 2002;81(4):311-20.

7. Thomas PA, Leck AK, Myatt M. Characteristic clinical features as an aid to the diagnosis of suppurative keratitis caused by filamentous fungi. BrJ Ophthalmol. 2005;89(12):1554-8.

8. Badiee P, Alborzi A, Farhoudi F. A case of Candida mediastinitis after dental extraction. J Infect Dev Ctries. 2011;5(1):75-8.

9. Tilak R, Singh A, Maurya OP, Chandra A, Tilak V, Gulati AK. Mycotic keratitis in India: a five-year retrospective study.J Infect Dev Ctries. 2010;4(3):171-4.

10. Reddy PS, Satyendran OM, Satapathy M, Kumar HV, Reddy PR. Mycotic keratitis. Indian J Ophthalmol.1972;20(3):101-8.

11. Ghannoum MA. Potential role of phospholipases in virulence and fungal pathogenesis. Clin Microbiol Rev. 2000;13(1):122-43.

12. Nayak N. Fungal infections of the eye--laboratory diagnosis and treatment. Nepal Med Coll J. 2008;10(1):48-63.

13. Thomas PA. Fungal infections of the cornea. Eye (Lond) 2003;17(8):852-62.

14. Chander J, Singla N, Agnihotri N, Arya SK, Deep A. Keratomycosis in and around Chandigarh: a five-year study from a north Indian tertiary care hospital. Indian J Pathol Microbiol. 2008;51(2):304-6.

15. Badiee P, Alborzi A, Nejabat M. Detection of Aspergillus keratitis in ocular infections by culture and molecular method. Int Ophthalmol. 2011;31(4):291-6.

16. Badiee P, Nejabat M, Alborzi A, Keshavarz F, Shakiba E. Comparative study of Gram stain, potassium hydroxide smear, culture and nested PCR in the diagnosis of fungal keratitis. Ophthalmic Res. 2010;44(4):251-6.

17. Khanal B, Kaini KR, Deb M, Badhu B, Thakur SK. Microbial keratitis in eastern Nepal. Trop Doct. 2001;31(3):168-9.

18. Chander J, Chakrabarti A, Sharma A, Saini JS, Panigarhi D. Evaluation of Calcofluor staining in the diagnosis of fungal corneal ulcer. Mycoses. 1993;36(7-8):243-5

19. Saha R, Das S. Mycological profile of infectious Keratitis from Delhi. Indian J Med Res. 2006;123(2):159-64.

20. Chowdhary A, Singh K. Spectrum of fungal keratitis in North India. Cornea. 2005;24(1):8-15.

21. Bharathi MJ, Ramakrishnan R, Vasu S, Meenakshi R, Palaniap pan R. Epidemiological characteristics and laboratory diagnosis of fungal keratitis. A three-year study. Indian J Ophthalmol. 2003;51(4):315-21.

22. Leck AK, Thomas PA, Hagan M, Kaliamurthy J, Ackuaku E, John $\mathrm{M}$, et al. Aetiology of suppurative corneal ulcers in Ghana and south India, and epidemiology of fungal keratitis. Br J Ophthalmol. 2002;86(11):1211-5.

23. Thomas PA. Mycotic keratitis--an underestimated mycosis. J Med Vet Mycol.1994:32(4):235-56.

24. Poole TR, Hunter DL, Maliwa EM, Ramsay AR. Aetiology of microbial keratitis in northern Tanzania. $\mathrm{Br} J$ Ophthalmol. 2002;86(8):941-2.

25. Vemuganti GK, Garg P, Gopinathan U, Naduvilath TJ, John RK Buddi R, et al. Evaluation of agent and host factors in progression of mycotic keratitis: A histologic and microbiologic study of 167 corneal buttons. Ophthalmology. 2002;109(8):1538-46.

26. Sharma S, Silverberg M, Mehta P, Gopinathan U, Agrawal V, Naduvilath TJ. Early diagnosis of mycotic keratitis: predictive value of potassium hydroxide preparation. Indian J Ophthalmol. 1998;46(1):31-5

27. Shokohi T, Nowroozpoor-Dailami K, Moaddel-Haghighi T. Fungal keratitis in patients with corneal ulcer in Sari, Northern Iran. Arch Iran Med. 2006;9(3):222-7.

28. Vajpayee RB, Angra SK, Sandramouli S, Honavar SG, Chhabra VK. Laboratory diagnosis of keratomycosis: comparative evaluation of direct microscopy and culture results. Ann Ophthalmol. 1993;25(2):68-71.

29. Tanure MA, Cohen EJ, Sudesh S, Rapuano CJ, Laibson PR. Spectrum of fungal keratitis at Wills Eye Hospital, Philadelphia, Pennsylvania. Cornea. 2000;19(3):307-12.

30. Vengayil S, Panda A, Satpathy G, Nayak N, Ghose S, Patanaik D, et al. Polymerase chain reaction-guided diagnosis of mycotic keratitis: a prospective evaluation of its efficacy and limitations. Invest Ophthalmol Vis Sci. 2009;50(1):152-6.

31. Badiee P, Alborzi A, Joukar M. Molecular assay to detect nosocomial fungal infections in intensive care units. Eur J Intern Med. 2011;22(6):611-5.

32. Badiee P, Alborzi A, Shakiba E, Farshad S, Japoni A. Susceptibility of Candida species isolated from immunocompromised patients to antifungal agents. East Mediterr Health J. 2011;17(5):425 30.

33. Badiee P, Alborzi A, Davarpanah MA, Shakiba E. Distributions and antifungal susceptibility of Candida species from mucosal sites in HIV positive patients. Arch Iran Med. 2010;13(4):282-7.

34. Ferrer C, Alio JL. Evaluation of molecular diagnosis in funga keratitis. Ten years of experience. J Ophthalmic Inflamm Infect. 2011;1(1):15-22.

35. Badiee P, Kordbacheh P, Alborzi A, Malekhoseini SA. Invasive fungal infection in renal transplant recipients demonstrated by panfungal polymerase chain reaction. Exp Clin Transplant. 2007;5(1):624-9.

36. Badiee P, Alborzi A, Malekhosseini SA, Nikeghbalian S, Shakiba E. Determining the incidence of aspergillosis after liver transplant. 
Exp Clin Transplant. 2010;8(3):220-3.

37. Badiee P, Alborzi A, Shakiba E, Ziyaeyan M, Pourabbas B. Molecular diagnosis of Aspergillus endocarditis after cardiac surgery. $J$ Med Microbiol. 2009;58(Pt 2):192-5.

38. Badiee P, Alborzi A. Assessment of a real-time PCR method to detect human non-cryptococcal fungal meningitis. Arch Iran Med. 2011;14(6):381-4.

39. Badiee P, Alborzi A. Detection of Aspergillus species in bone marrow transplant patients. J Infect Dev Ctries. 2010;4(8):511-6.

40. Badiee P, Alborzi A, Vojdani R, Shakiba E, Rasouli M, Ravanfar P, et al. Early diagnosis of systemic candidiasis in bone marrow transplant recipients. Exp Clin Transplant. 2010;8(2):98-103.

41. Ferrer C, Munoz G, Alio JL, Abad JL, Colomm F. Polymerase chain reaction diagnosis in fungal keratitis caused by Alternaria alternata. Am J Ophthalmol. 2002;133(3):398-9.

42. Anand A, Madhavan H, Neelam V, Lily T. Use of polymerase chain reaction in the diagnosis of fungal endophthalmitis. Ophthalmology. 2001;108(2):326-30.

43. Kumar M, Mishra NK, Shukla PK. Sensitive and rapid polymerase chain reaction based diagnosis of mycotic keratitis through single stranded conformation polymorphism. Am J Ophthalmol. 2005;140(5):851-857.

44. Kim E, Chidambaram JD, Srinivasan M, Lalitha P, Wee D, Lietman TM, et al. Prospective comparison of microbial culture and polymerase chain reaction in the diagnosis of corneal ulcer. Am JOphthalmol. 2008;146(5):714-23.

45. Dahlgren MA, Lingappan A, Wilhelmus KR. The clinical diagnosis of microbial keratitis. Am J Ophthalmol. 2007;143(6):940-944.

46. Badiee Parisa, Alborzi A, Shakiba E, Ziyaeyan M, Rasuli M. Molecular Identification and In-Vitro Susceptibility of Candida albicans and C. dubliniensis Isolated from Immu-nocompromised Patients. Iranian Red Crescent Medical Journal. 2009;11(4):391-397.

47. Day S, Lalitha P, Haug S, Fothergill AW, Cevallos V, Vijayakumar R, et al. Activity of antibiotics against Fusarium and Aspergillus. $\mathrm{Br}$ JOphthalmol. 2009;93(1):116-9.

48. Rahman MR, Johnson GJ, Husain R, Howlader SA, Minassian DC. Randomised trial of $0.2 \%$ chlorhexidine gluconate and $2.5 \%$ natamycin for fungal keratitis in Bangladesh. Br J Ophthalmol. 1998;82(8):919-25.

49. Sponsel W, Chen N, Dang D, Paris G, Graybill J, Najvar LK, et al Topical voriconazole as a novel treatment for fungal keratitis.
Antimicrob Agents Chemother 2006;50(1):262-8.

50. Ozbek Z, Kang S, Sivalingam J, Rapuano CJ, Cohen EJ, Hammersmith KM. Voriconazole in the management of Alternaria keratitis. Cornea. 2006;25(2):242-4.

51. Bernal MD, Acharya NR, Lietman TM, Strauss EC, McLeod SD Hwang DG. Outbreak of Fusarium keratitis in soft contact lens wearers in San Francisco. Arch Ophthalmol. 2006;124(7):1051-3.

52. Prajna NV, Mascarenhas J, Krishnan T, Reddy PR, Prajna L, Srinivasan $\mathrm{M}$, et al. Comparison of natamycin and voriconazole for the treatment of fungal keratitis. Arch Ophthalmol. 2010;128(6):672-8.

53. Hariprasad SM, Mieler WF, Lin TK, Sponsel WE, Graybill JR. Voriconazole in the treatment of fungal eye infections: a review of current literature. Br J Ophthalmol. 2008;92(7):871-8.

54. O'Day DM, Head WS, Robinson RD, Clanton JA. Corneal penetration of topical amphotericin B and natamycin. Curr Eye Res. 1986;5(11):877-82.

55. Alfonso EC, Cantu-Dibildox J, Munir WM, Miller D, O'Brien TP Karp CL, et al. Insurgence of Fusarium keratitis associated with contact lens wear. Arch Ophthalmol. 2006;124(7):941-7.

56. Lau D, Fedinands M, Leung L, Fullinfaw R, Kong D, Davies G, et al. Penetration of voriconazole, $1 \%$, eyedrops into human aqueous humor: a prospective open-label study. Arch Ophthalmol. 2008;126(3):343-6.

57. Tu EY, McCartney DL, Beatty RF, Springer KL, Levy J, Edward D. Successful treatment of resistant ocular fusariosis with posaconazole(SCH-56592). Am J Ophthalmol. 2007;143(2):222-227.

58. Siatiri H, Daneshgar F, Siatiri N, Khodabande A. The effects of intrastromal voriconazole injection and topical voriconazole in the treatment of recalcitrant Fusarium keratitis. Cornea. 2011;30(8):872-5.

59. Sharma N, Agarwal P, Sinha R, Titiyal JS, Velpandian T, Vajpayee RB. Evaluation of intrastromal voriconazole injection in recalcitrant deep fungal keratitis: case series. $\mathrm{Br} J$ Ophthalmol. 2011;95(12):1735-7

60. Tuli SS. Fungal keratitis. Clin Ophthalmol. 2011;5:275-9.

Please cite this paper as:Badiee P. Mycotic Keratitis, a State-of-theart Review. Jundishapur J Microbiol. 2013; 6(5): e8561. DOI: 10.5812 jjm.8561 